\title{
Numerical study on Sinking Mooring System of Immersed Tube Tunnel Construction
}

\author{
Qiu Zhengzhong ${ }^{1, a^{*}}$ and Wan Meng ${ }^{1, b}$ \\ ${ }^{1}$ Technology Center of CCCC Second Harbor Engineering Co., Ltd, Wuhan 430040, China \\ aqiuzhengzhong@126.com, b275949596@qq.com \\ * please mark the corresponding author with an asterisk
}

\begin{abstract}
Keywords: Immersed tube; 3D potential flow theory; Transfer function; Mooring system; Stern cable. Abstract. Relying on a large immersed tube tunnel, based on 3D potential flow theory, the tube-floating barge mooring system was calculated and analyzed by hydrodynamic software SESAM. The mechanical characteristics of the mooring rope and the motion response time-history curve of the tube-floating were obtained under the given construction conditions, which is significative for the practical projects.
\end{abstract}

\section{Introduction}

With the development of globe economic and technology, immersed tunnel shows obvious superiority with its unique construction method as a special type of sea-crossing or river-crossing engineering. The floating, sinking and installation of the immerse tunnel plays an important role in the whole immersed tube tunnel construction process, meanwhile, the speed of immersion have a great influence on the quality and schedule of the whole immersed tube tunnel construction process. On the one hand, the immersed process is a complicated system; on the other hand, the immersed process is influenced by the wind, wave, flow, etc. Thus, the mechanical analysis on the mooring system contributes to predict the hazardous conditions between the sinking process and provide a reference for the practical sinking project. A model experiment is necessary for the Sinking Mooring System because of its complexity. In this paper, the tube-floating barge mooring system was calculated and analyzed based on the $3 \mathrm{D}$ potential flow theory ${ }^{[1-2]}$.

\section{Model Built}

Relying on a large immersed Tube, the motion and dynamic response of tunnel elements in the immersion is calculated and analyzed by hydrodynamic software SESAM. The necessary models are: genie, used to build the dynamic model of tube floating system, create the panel model T1 and the quality model T3; HydroD, based on 3D potential flow theory to calculate the hydrodynamic coefficient of immersed Tube; Deepc, used to analyze and calculate the coupling tube floating system.

The model of tube floating system is built based on Genie, a adjustment to the displacement and quality is made based on loading manual(Figure 1). 


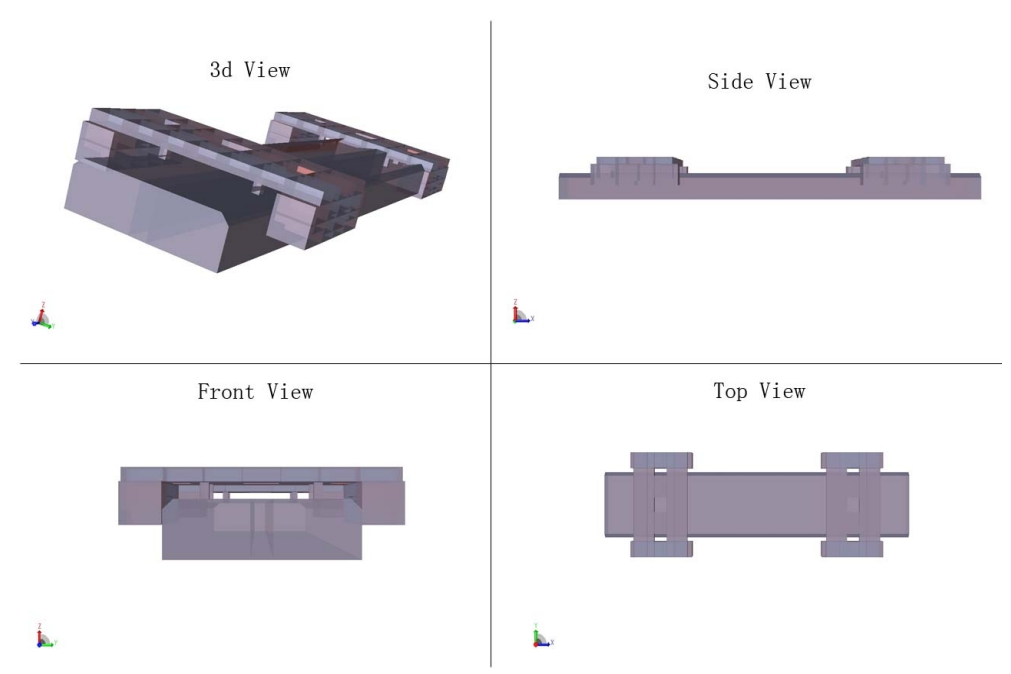

Fig. 1 Tube-floating barge hydrodynamic model

\section{Result and analysis}

The transfer function of motion response. The hydrodynamic model is built based on Genie, which can be frequency-domain analyzed by HydroD. The angular velocity has 40 wave frequencies, ranges between $0.01 \mathrm{rad} / \mathrm{s} \sim 2 \mathrm{rad} / \mathrm{s}$. The RAO results of floating rolling, pitching and heaving are shown in figure $2 \sim 4$.
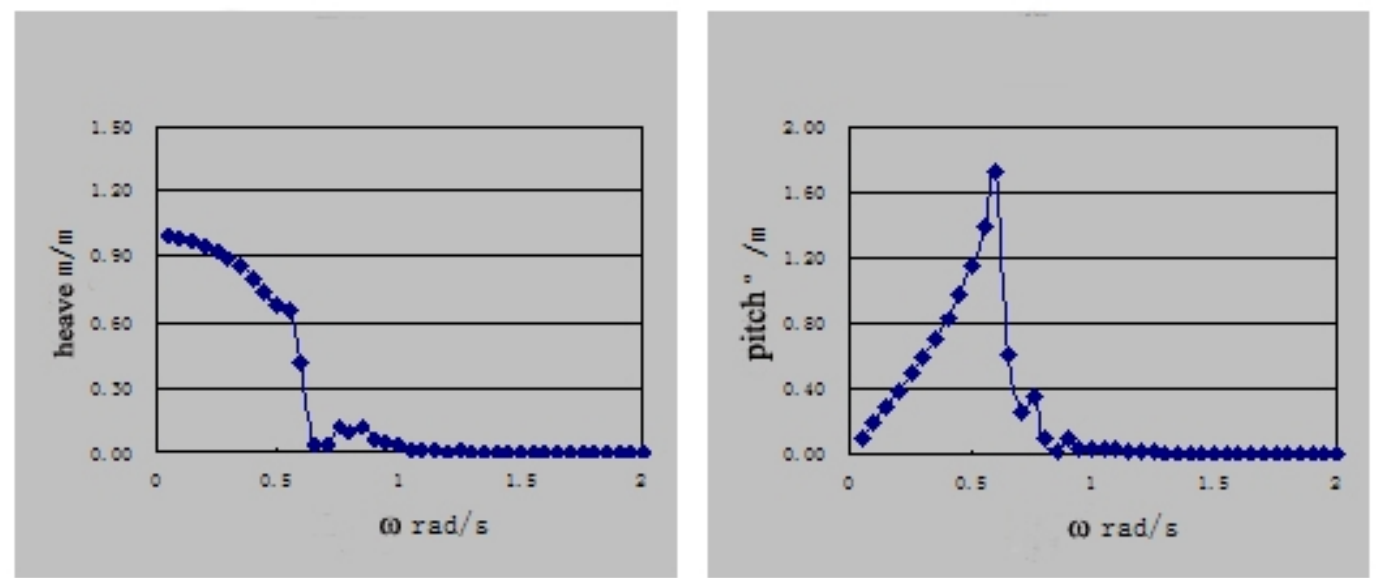

Fig.2 Transfer function of heaving response Fig.3 Transfer function of pitching response

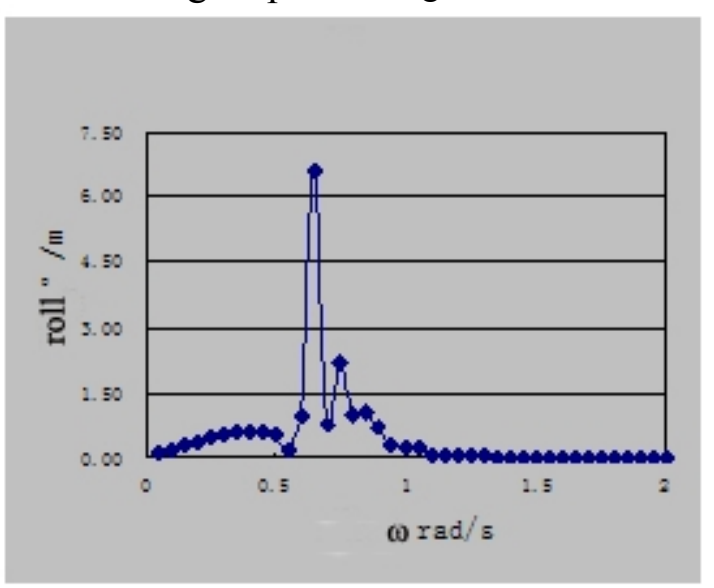

Fig.4 Transfer function of rolling response

As can be seen in fig. 3 , the heaving amplitude of floating in a unit amplitude tends to $1 \mathrm{~m}$ when the encounter frequency tends to $0 \mathrm{rad} / \mathrm{s}$, meanwhile, the heaving amplitude of floating in a unit amplitude tends to $0 \mathrm{~m}$ when the encounter frequency tends to infinity. That is, the floating moves along with the 
water quality when the wave length tends to infinity, while the floating has little response when the wave length tends to 0 ; The natural rolling period is $9.88 \mathrm{~s}$, and the pitching and heaving period are $12.08 \mathrm{~s}$ and $11.02 \mathrm{~s}$ respectively, the synchronism rolling periodic interval of the tube-floating barge range between $7 \mathrm{~s} \sim 13 \mathrm{~s}$. A significant movement may occur when suffered the above waves. Therefore, the risk of mooring system and pipe joint caused by the waves must be careful consideration with the period above $7 \mathrm{~s}$.

Comparison and analysis of mooring schemes. The Jonswap3 spectrum is used to analyze the tube-floating barge mooring system, the significant wave height is $0.8 \mathrm{~m}$, the spectrum peak period is $6 \mathrm{~s}$, the cable pretension range between $10 \mathrm{t} \sim 15 \mathrm{t}$ according to the practical situation. The cable is $30^{\circ}$ in aperture angle and $349 \mathrm{~m}$ in length, the mooring lay out as shown below fig.5 6, a stern line is increased in the five-cable mooring than the four-cable mooring scheme.

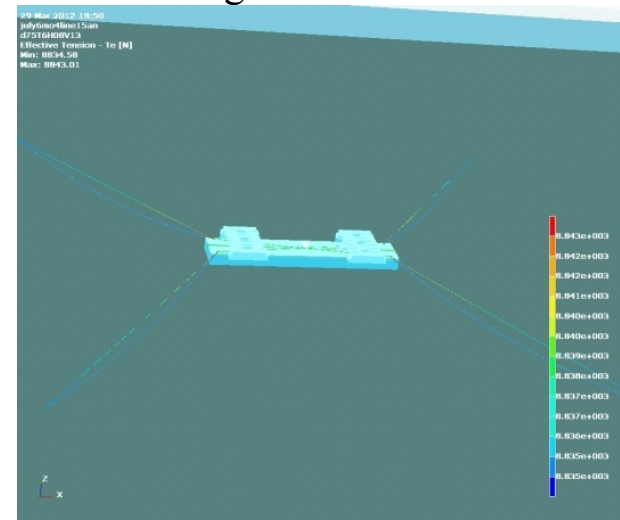

Fig.5 Four-cable mooring

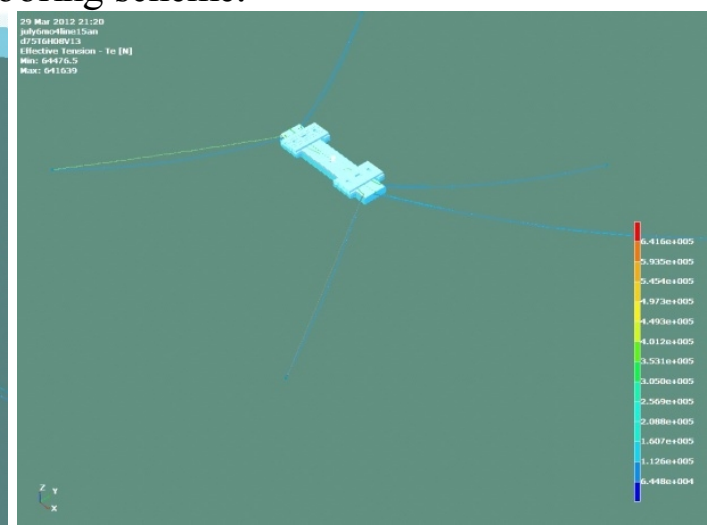

Fig.6 Five-cable mooring

Calculation analysis of static results. The purpose of static calculation is to analyze the stable state of the floating without the consideration of dynamic load, offering the initial condition for the dynamic calculation in addition. The influence of the second order wave drift force and the drag force on the floating are merely considered, the constant load is added to the mooring system to calculate the drifting of floating and the initial tension of mooring rope. The calculation results are as follows in table1.

Tab.1 The static calculating results of mooring force

\begin{tabular}{c|c|c|c|c|c|c|c|c|c}
\hline \multirow{3}{*}{$\begin{array}{c}\text { Mooring } \\
\text { layout }\end{array}$} & \multicolumn{4}{|c|}{ 4-cable mooring } & \multicolumn{4}{c}{ 5-cable mooring } & \multirow{2}{*}{ Stern-cable } \\
\cline { 2 - 9 } & Backward-flow side & Incident-flow side & \multicolumn{2}{|c|}{$\begin{array}{c}\text { Backward-flow } \\
\text { side }\end{array}$} & \multicolumn{2}{|c|}{ Incident-flow side } & \\
\cline { 2 - 9 } & $1 \#$ cable & $2 \#$ cable & $3 \#$ cable & $\begin{array}{c}4 \# \\
\text { cable }\end{array}$ & $1 \#$ cable & $2 \#$ cable & $\begin{array}{c}3 \# \\
\text { cable }\end{array}$ & $\begin{array}{c}4 \# \\
\text { cable }\end{array}$ & \\
\hline Force $(\mathrm{t})$ & 19.20 & 6.96 & 65.78 & 46.64 & 8.96 & 7.12 & 65.48 & 47.73 & 16.14 \\
\hline
\end{tabular}

As can be seen in tab.1; the static mooring force is caused by the wave drift force and the drag force. The nonuniformity of static strain behaves obviously because of the existence of flow and wave angle, for example, the strain of the two cables in the backward-flow side of 4-cable mooring distinguish nearly 3 times. Stern-cable is added in 5-cable mooring to limit the gap of the maximum static mooring force in backward-flow side, which contributes to enhance the stability of mooring system. The nonuniformity of static strain in incident-flow side is less than backward-flow side. The existence of stern cable has no obvious impact on the distribution of mooring force in the incident-flow side.

Calculation analysis of dynamic results. Dynamic calculation is applied based on the scheme of 4-cable and 5-cable, and the calculation results are analyzed according to DNV requirement. The distribution of extremum value is 3-parametres-Weibull distribution and the cable reliability is $95 \%$. The calculation results can be seen in tab.2 and tab.3. 
Tab.2 Dynamic force of 4-cable mooring

\begin{tabular}{c|c|c|c|c|c}
\hline \multicolumn{3}{c|}{ 1\#cable } & \multicolumn{3}{c}{ 2\#cable } \\
\hline $\begin{array}{c}\text { Max. value } \\
(\mathrm{t})\end{array}$ & $\begin{array}{c}\text { Mean value } \\
(\mathrm{t})\end{array}$ & $\begin{array}{c}95 \% \text { reliability } \\
(\mathrm{t})\end{array}$ & $\begin{array}{c}\text { Max. value } \\
(\mathrm{t})\end{array}$ & Mean value $(\mathrm{t})$ & 95\% reliability (t) \\
\hline 26.80 & 19.54 & 25.51 & 6.15 & 5.94 & 6.06 \\
\hline \multicolumn{3}{c|}{ 3\#cable } & & & $4 \#$ cable \\
\hline $\begin{array}{c}\text { Max. value } \\
(\mathrm{t})\end{array}$ & $\begin{array}{c}\text { Mean value } \\
(\mathrm{t})\end{array}$ & $\begin{array}{c}95 \% \text { reliability } \\
(\mathrm{t})\end{array}$ & $\begin{array}{c}\text { Max. value } \\
(\mathrm{t})\end{array}$ & Mean value $(\mathrm{t})$ & $95 \%$ reliability $(\mathrm{t})$ \\
\hline 81.8 & 47.02 & 75.20 & 91.74 & 65.62 & 83.47 \\
\hline
\end{tabular}

Tab.3 Dynamic force of 5-cable mooring

\begin{tabular}{|c|c|c|c|c|c|c|c|c|}
\hline \multicolumn{3}{|c|}{ 1\#cable } & \multicolumn{3}{|c|}{ 2\#cable } & & & \\
\hline $\begin{array}{l}\text { Max. } \\
\text { value } \\
\text { (t) }\end{array}$ & $\begin{array}{l}\text { Mean } \\
\text { value } \\
\text { (t) }\end{array}$ & $\begin{array}{c}95 \% \\
\text { reliability } \\
\text { (t) }\end{array}$ & $\begin{array}{l}\text { Max. } \\
\text { value } \\
\text { (t) }\end{array}$ & $\begin{array}{l}\text { Mean } \\
\text { value } \\
(\mathrm{t})\end{array}$ & $\begin{array}{c}95 \% \\
\text { reliability } \\
(\mathrm{t})\end{array}$ & & & \\
\hline 9.97 & 9.04 & 9.67 & 7.6 & 7.11 & 7.36 & & & \\
\hline \multicolumn{3}{|c|}{ 3\#cable } & \multicolumn{3}{|c|}{ 4\#cable } & \multicolumn{3}{|c|}{ 5\#cable ( Stern-cable ) } \\
\hline $\begin{array}{l}\text { Max. } \\
\text { value } \\
\text { (t) }\end{array}$ & $\begin{array}{l}\text { Mean } \\
\text { value } \\
\text { (t) }\end{array}$ & $\begin{array}{c}95 \% \\
\text { reliability } \\
\text { (t) }\end{array}$ & $\begin{array}{l}\text { Max. } \\
\text { value } \\
\text { (t) }\end{array}$ & $\begin{array}{l}\text { Mean } \\
\text { value } \\
\text { (t) }\end{array}$ & $\begin{array}{c}95 \% \\
\text { reliability } \\
(\mathrm{t})\end{array}$ & $\begin{array}{l}\text { Max. } \\
\text { value } \\
(\mathrm{t})\end{array}$ & $\begin{array}{l}\text { Mean } \\
\text { value } \\
\text { (t) }\end{array}$ & $\begin{array}{c}95 \% \\
\text { reliability } \\
\text { (t) }\end{array}$ \\
\hline 96.29 & 48.13 & 76.53 & 90.89 & 65.27 & 84.7 & 17.87 & 16.30 & 17.37 \\
\hline
\end{tabular}

As can be seen in tab.2 and tab.3, Compared with the static calculating results, the strain of the two cables in the backward-flow side of 4-cable mooring distinguish nearly 4 times. That is, the eccentric load effect will be further amplified. Dynamic response factor should be considered in cable tension and immersed tube motion, which has a significant impact on the security mooring system. The existence of stern-cable has a significant improvement in the balance of mooring force in the backward-flow side under the oblique wave and oblique flow action, while the mooring force in the incident -flow side has little changed.

Dynamic displacement of tube-floating. According to the related engineering experience, the roll amplitude in tube-floating barge mooring system is no more than $1 \%$. The influence of rolling can be ignored because of the big rolling damping. In this paper, the influence of stern-cable on longitudinal shift of the tube-floating barge mooring system is mainly considered, the surging curve of tube-floating can be seen in fig. 7 and fig. 8 .

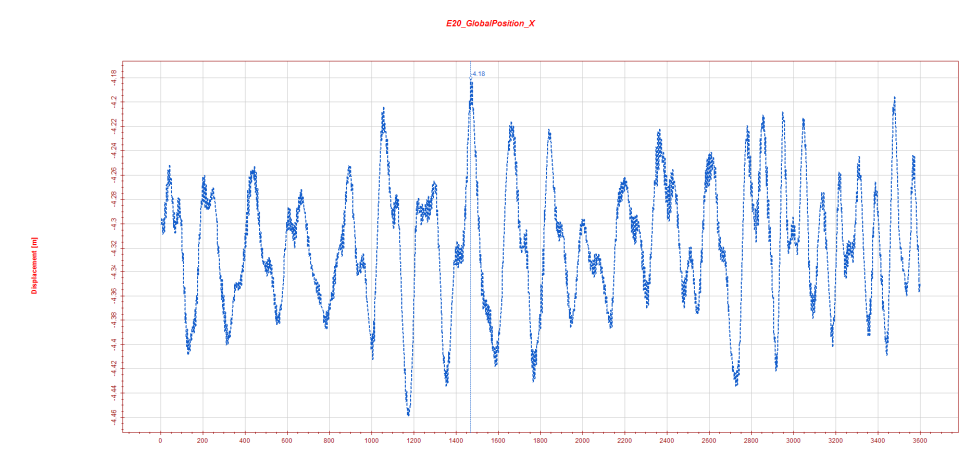

Fig.7 Surging curve of 4-cable tube-floating 


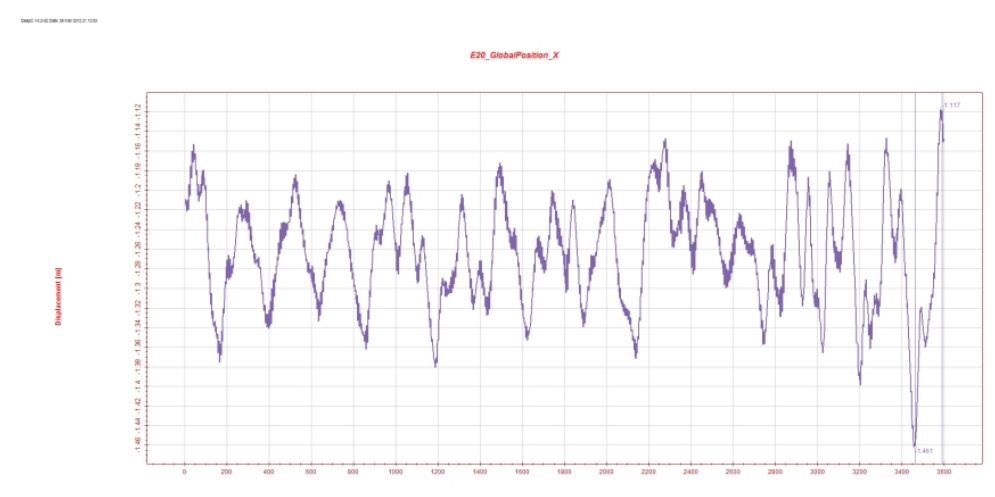

Fig. 8 Surging curve of 5-cable tube-floating

As can be seen in the above figures, the peak surge in 4-cable scheme is $-4.46 \mathrm{~m} /-4.18 \mathrm{~m}$, the average vertical drift distance is $-4.32 \mathrm{~m}$, and the maximum amplitude is $0.14 \mathrm{~m}$. In the 5-cable scheme, the peak surge is $-1.26 \mathrm{~m} /-1.12 \mathrm{~m}$, the average vertical drift distance is $-1.26 \mathrm{~m}$, and the maximum amplitude is $0.01 \mathrm{~m}$. the drift distance has been effectively controlled because of the existence of stern-cable, the peak tension of stern-cable is controlled within 20ton. Compared with no stern-cable, the existence of stern-cable effectively limits the drift distance and the motion amplitude of longitudinal shift.

\section{Conclusion}

In this article, the tube-floating barge mooring system was calculated and analyzed based on hydrodynamic software SESAM. The results show that: 1) The maximum cable force of static and dynamic condition in mooring system have no more than $100 \mathrm{t}$, which provide the basis for the following cable material and the selection of cross-section. 2) The existence of stern-cable has a significant improvement in the balance of mooring force in the backward-flow side under the oblique wave and oblique flow action, while the mooring force in the incident -flow side has little changed. 3) The join of stern-cable improves the force system obviously. Compared with no stern-cable, the existence of stern-cable effectively limits the drift distance and the motion amplitude of longitudinal shift, which is useful to the motion control of tube-floating and the security of mooring system.

\section{References}

[1] Chen Shuo. Experimental Investigation on Tension Characteristics of Mooring Cables in Tunnel Tube Immersion Motion[D]. Wuhan University of Technology, 2012.

[2] Lin Liyang. Experimental Investigation on the Motion and Dynamic Response of Tunnel Element in the process of Immersing[D]. Wuhan University of Technology, 2012.

[3] Xu Wei. Study on Numerical Calculation of Wave-induced Motions and loads for Trimaran[D]. Shanghai Jiao Tong University, 2008.

[4] MO Rui-fang, LIU Ya-dong. The Analysis and Short-term Prediction of Sea Keeping of a 15000ton Semi-submerged Ship[J]. Ship Engineering, 2011. 